\title{
Let's Improv It: \\ The Embodied Investigation of Social Collaboration
}

\author{
Klara Lucznik $^{*}$ iD , Abigail Jackson1 ${ }^{1}$, Aska Sakuta², \& Eleonora Siarava ${ }^{3}$ \\ 1 Plymouth University, UK \\ 2 University of Chichester, UK \\ ${ }^{3}$ Aristotle University of Thessaloniki, Greece \\ *Klara.Lucznik@CogNovo.eu
}

Received 6 May 2017; accepted 26 September 2017; published 21 November 2017.

\begin{abstract}
How do we share embodied knowledge? How do we understand the world through our bodies? How can we effectively interpret and communicate somatic experiences to a wider audience? These questions emerged during a collaborative research project Let's Improv It (August 2016, Plymouth University), which set out to explore how kinaesthetic empathy and multisensory perception help us to understand our own actions, intentions and emotions, as well as those of others. We additionally questioned the role and perception of physical and emotional touch within embodied knowledge.
\end{abstract}

After a five-day practice-led investigation, a 20-minute improvised somatic movement score was developed with the aim of providing a novel experience of touch and movement.

The authors collectively delivered the score and reflected on the outcomes of this experience over the course of a year (2016-2017). In this paper, we explore how our research project expanded the boundaries of the conventional concepts of knowledge and cognition. We see such participatory sessions, in which movement and embodied experience freely unfold in time and space, as a 'laboratory' in which we examine the underlying mechanisms of collaboration. We reflect on how such an experience can be seen as a creative process, or as an emergent, collaborative artwork. The participants are both the creators and, simultaneously, the audience of our improvised experience. The experience provided a non-judgmental context for physical engagement and observation, which is an outcome that will be introduced 
alongside participants' feedback. Overall, the project revealed that shared embodied knowledge is highly appreciated, particularly among those without previous experience with embodied enquiry or movement research.

Keywords: dance; embodied cognition; empathy; improvisation; participatory performance.

\section{Introduction}

As a social species, humans are experts in collaboration (Theiner, 2014). However, our understandings of the 'social glue' (Dijksterhuis, 2005, p. 207) that allows us to coordinate complex actions within dynamically changing environments is still limited and speculative in nature. In this research, we focus on how embodied knowledge and embodied cognition in social interactions (Ignatow, 2007) can be investigated through collaborative movement improvisation as a mode of practice research. Movement improvisation is a free-form, momentary practice, in which participants simultaneously generate and share their ideas without pre-planning or preconception, making each improvisation a unique singular social encounter (Blom \& Chaplin, 1988). Such a setting offers an opportunity to observe and experience spontaneous social interactions as they happen (Benjamin, 2002, p. 43; Sawyer, 2000). Due to the mostly non-verbal character of the practice, it allows greater focus on embodied means of communication.

Ribeiro and Fonseca (2011) suggested that collaboration and communication between improvisers are mediated by 'kinaesthetic empathy.' This they define as the ability to understand others' actions and emotions through embodied feelings, which tend to match others' states. Kinaesthetic empathy allows us to anticipate the intentions of others and to make decisions based on shared cognitive structures. The mirror neurons hypothesis (Gallese, Keysers, \& Rizzolatti, 2004) was suggested as a possible neuronal mechanism that enables awareness of others' emotional states and movement intentions. They suggest that we do not just perceive (i.e., see or hear) others' actions or emotions, but rather experience them in the same way as our own actions. The same neural structures are activated during first-person ('I feel it') and third-person ('I see her/him feeling it') experiences. Thus, social cognition is not only a thinking process in which individuals simulate each other's minds (Goldman \& Sripada, 2005), but an experiential, embodied one, wherein we sense each other's physical and emotional states (Gallese, 2003).

This almost automatic, yet highly interdependent and interactive character of basic human interactions is highlighted by the joint action theory (Sebanz, Bekkering, \& Knoblich, 2006). The theory describes how people manage to coordinate their actions swiftly and effortlessly without much verbal communication. To coordinate any joint action, for instance, something as simple as 'moving a table together,' people have to: (1) share representations of the collaborative task; (2) predict actions 
of partners in an interaction; and (3) integrate those predictions with one's own actions. Hence, any social interaction or shared action needs constant, improvised adjustment of each other's plans and actions.

We cannot speak about the embodied aspect of social interactions without discussing the role of touch. Touch has a crucial role in human development, especially within its social aspect (White, 2004). Tactile communication is as important in early development (Feldman, 2011) as it is in adulthood relationships (Chatel-Goldman, Congedo, Jutten, \& Schwartz, 2014). David Linden (2015, p. 7), when analyzing social interaction in various situations including caregiving, sports, and social support, argues that skin can be seen as a social organ. Social touch can promote trust and cooperation (Jones \& Yarbrough, 1985; Kraus, Huang, \& Keltner, 2010), and allow individuals to read and communicate emotions (Hertenstein, Keltner, App, Bulleit, \& Jaskolka, 2006).

Drawing on the perspectives above, social interactions can be seen as deeply embodied, improvisational acts that happen in our everyday life. The current paper focuses on the social processes of collaboration through the perspective of real-time, embodied interactions in movement improvisation.

\section{The Process of Exploration}

Our interdisciplinary backgrounds (dance, music, developmental/clinical psychology, cognitive science, eastern philosophy, and cultural studies) brought together a variety of perspectives and approaches to the idea of improvisation, which resulted in a group dynamic that constantly shifted and changed. This diversity was contrasted by a single commonality: as all members held a background of practicebased or practically grounded research, our discussions tended to blur with our hands-on investigation. Our daily work was held in studio spaces and outdoor locations, wherein we invested ourselves holistically (i.e., both physically and mentally) in the unfolding topics of the project. In one session, we would improvise freely in response to a set of prompts deriving from scientific literature; in another session we would brainstorm our ideas by creating word clouds with the notes that we had taken throughout the preceding days.

Related cognitive theories on kinaesthetic empathy, joint actions, the role of touch, etc. were introduced through radio lectures, ${ }^{1}$ during which the group listens loosely as they move through their physical warm up. The listeners responded, or not, to what they heard, whether it manifested as influences in their movement or flow of thought. This way of providing information allowed the movers to directly integrate new knowledge into their physical practice, share that experience with others, and

\footnotetext{
1 The idea of presenting the theoretical background of the project through a radio lecture format was inspired by the classes of Rick Nodine, who used similar format to introduce physiological knowledge to students (London, Spring 2016).
} 
to reflect on the experience in an embodied way. We noticed that the immediacy with which the information became embodied and integrated in movement allowed for a more fluid, quick communication of our moment-to-moment interpretations of the presented material. Noticing the differences in which one piece of information can be processed allowed for each individual to self-reflect, both physically and cognitively, on the unique nature of their own perspective. The radio lectures created the foundation of a space in which fluid and immediate communications and reflections would occur, priming the dynamics of the group for further improvisational movement explorations.

We decided that the most valuable contribution of our process is to highlight the efficacy and significance of improvisational (or explorative) discourse-both in the verbal and non-verbal sense-as a tool for studying social collaboration. Communicating this to those who do not regularly participate in improvisational modes of investigation (whether it be academic research, professional work, or self-discovery) became our main area of interest. We concluded that the best way to share our findings is to provide experience, rather than explanation. We sought ways to translate our ideas, sensations and embodied reflections into a structured 'experience space' that invites others to delve into this non-linear process of exploration. We aimed to show how 'solutions' and 'answers' are not necessarily the most important elements in the process of 'being'; there need not be an 'end-goal,' but there is always a need for curiosity, and one can merge with this process of investigation through a nonverbal, sensory mode of improvisation.

\section{The Experience}

Through the five-day practice-led investigation, we developed a 20-minute improvised somatic movement experience, primarily aimed at non-dancers. This experience has been delivered twice so far: once at the end of the ColLaboratoire Summer School, and once at the Dance and Somatic Practices Conference in Coventry (July 2017). One distinct characteristic of the experience is that it is delivered in darkness and silence, drawing on the idea that a large part of human knowledge is shared and developed through embodied and kinaesthetic experiences (Ignatow, 2007). As facilitators, we collectively and non-verbally guide participants through our developed improvisation scores. While the experience has an overall structure and a rough estimate of duration, it is designed to allow fluidity in its transitions between the scores.

The participants are invited to enter a dark "experience space," with only dim lighting placed just for safety. The intention is to reduce visual information-one of the most dominant sensory inputs in everyday life (Posner, Nissen, \& Klein, 1976) —as much as possible, in order to sharpen participants' haptic/tactile perception and proprioception. By sharpening these non-visual sensory pathways, we aim to highlight the experiential (rather than descriptive or interpretive) aspect of the 
movement improvisation that would follow. At the beginning, participants are asked to lie on the floor, close their eyes, and follow a stream of imagery tasks which aims to heighten their somatic consciousness-their awareness of bodily sensations. After the verbal guidance, participants are invited to stand up and are told that they may receive a tactile sensation, upon which they can "simply react to the touch received, with any kind of moving reaction." The facilitators give participants various forms of tactile input (e.g., brushing with fingers, pressing with palms, giving weight through the torso, etc.) and gently guide them (non-verbally) to connect with each other. This is followed by the introduction of more interactive scores, based on basic social principles such as leading and following, mimicry, and maintaining a shared gaze (Dijksterhuis, 2005, p. 207). These scores are introduced in a random, momentum-based sequence, with the six facilitators approaching each participant one by one. The participants are encouraged to explore space and movement independently, or by interacting with each other. The movement improvisation gradually unfolds as participants become accustomed to the sensory space, start to experiment with momentum, and, eventually, travel through the space in relation to others. The experience involves multiple simultaneously occurring variations in forces and dynamics, which eventually becomes a shared run around the room, and then a physical rest (Figure 1).

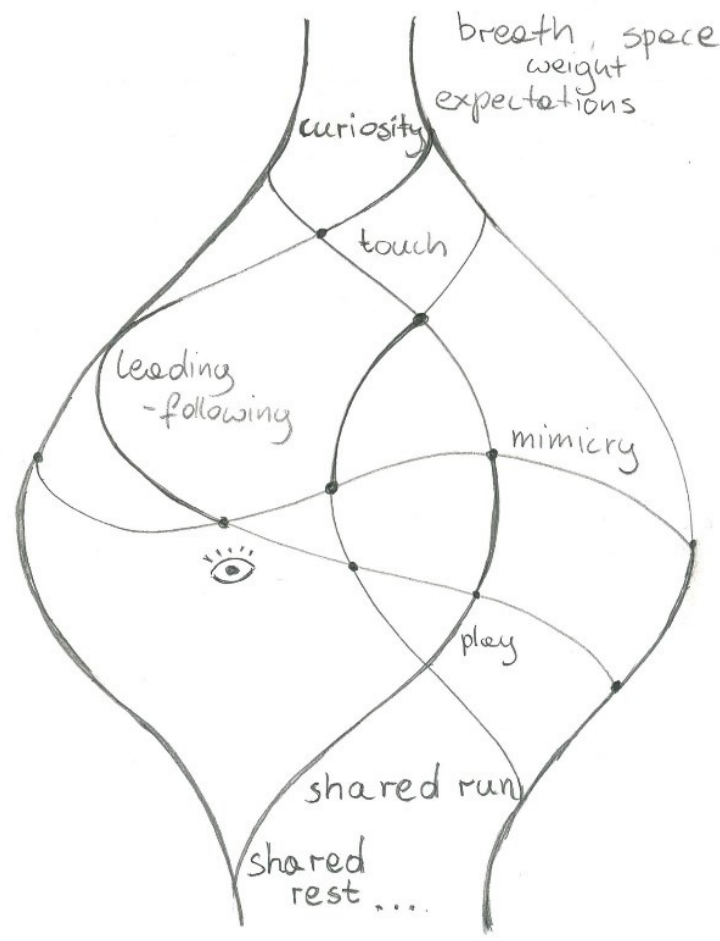

Figure 1. The graphic representation of improvisational score used in the shared experience. 
After the experience, we open a conversation among the group members wherein participants are invited to share and exchange their thoughts and reflections on the experience. Here, participants have the opportunity to recall, put into words, and freely communicate their experiences. For the two most recent deliveries, spoken responses were recorded on a voice recorder, while written responses were gathered through a short questionnaire. Participants' feedback was used to build an indepth reflection on the findings of our project; this will be discussed below.

\section{Reflections}

By inviting non-dancers to participate in our somatic movement experience, we have expanded the boundaries of the conventional idea of performance. While the concept of "movement/dance improvisation" can typically be perceived by nondancers as an activity open only to the "performers" of the event (Carter, 2000), in our session, the participants were the performers, movers, and creators of the work, all at once. At the beginning, participants are told that they can sit out and observe the workshop if they wish. However, whether they explore movement on their own or observe others' movements in a static position, all individuals are partakers in the occasion, continuously shifting, changing, and crafting the interpersonal, kinaesthetic connections (Foster, 2003). They recognized this particular quality of experience, commenting that there were newly found emotional and physical sensations evoked by the environment, yet arising from within:

Just watching, observing the connections and shapes was an amazing experience. The touching would have been awkward, but it was liberating! A shared experience of the senses!

It was through perceiving, sensing, and acting within this transformative environment that the participants became attuned to their individual embodiments and encountered the dense currents of 'kinesthetic touch':

The stage where everyone moved in the space, bonding through touch with each other, became deeply sensual over time. I had never thought that touch, with people I don't even know, could be so sensual.

This type of process is mentioned by Savrami, who claims that, in dance improvisation, the 'living body' is invited to directly respond to internal or external stimuli through the experiential practice of active bodily perception (Savrami, 2017).

The darkness of the room played an important role for the experience in creating a visual and social ambiguity:

Darkness supported special liberating moments connecting with others. Touch \& kinesthetically. Hands connecting. Shapes/ movement/ connection. 
In everyday life, we are hyper aware of others' appearance, which holds encoded and decodable 'social meanings' (Burgoon, Guerrero \& Floyd, 2016). For instance, an individual's outfit can hold intentionally or unintentionally encoded 'meanings' on the individual's gender, cultural background, etc. This information is then processed by others, thus influencing their decisions and choices. The lack of light in the room creates an environment in which participants are deprived of such visually-based social cues.

I felt that physical interactions were more sensual and deprived of social meaning. I felt triggered into some actions just by seeing other people involved in them and not because I was invited to.

Consequently, they must rely on other senses such as hearing, touch, and kinesthesia, in order to develop social connections with others, while having little to no knowledge of 'who' that person is, nor what one's socially prescribed relationship with that other person is (Gallese, 2003; Hertenstein, Keltner, App, Bulleit, \& Jaskolka, 2006; Ribeiro \& Fonseca, 2011; Verstegen 2005, p.22). Sensing another's presence can guide one to move closer or further; feeling another's touch can cause one's body to react with new movement. Even listening to the vibrations of the floor can change the state of one's body. In other words, the process of social 'meaning-making' shifts into a tactile and kinaesthetic experience of others. This shift opened up the possibility to 'see' others through a different lens, as well as to reflect on oneself in a more raw (bare) way, which resulted in the fading of 'roles' in their traditional (social) sense; the lack of visual input created a non-hierarchical, inclusive and transformative environment.

I liked seeing people dance-to me it felt like they were creating an "energy" and it was being shared. I could "feel" the energy.

The fluidity in which the participants' 'roles' shifted (e.g., mover to perceiver to creator), as well as the interconnectedness of these roles (e.g., observers and movers influencing each other) highlighted the idea of joint actions (Sebanz et al., 2006) in that participants fluidly and non-verbally negotiated their continuously shifting, interdependent 'roles' in the space, thereby inherently sharing a collaborative task, predicting actions of others, and integrating those predictions into their next action.

Like visual processing, verbal communication is another, highly dominant tool for social interaction ( $\mathrm{Ng} \&$ Bradac, 1993). The lack of verbal instructions in the experience, alongside the tactile interactions initiated by the facilitators, led the participants to 'forget' about speaking (and what had been said) for the duration of the experience, thereby creating a collectively facilitated, extra-ordinary space of full non-verbal interaction.

There was a moment when my hands were touching another person's hands and very slowly our hands moved away from each other... But somehow the connection was still there, or the thought of the connection at least was. I was led away, engaging in other 
interaction, however after a while, the exact same situation happened (hands touching) with the same person, but now in a less "explorative" way, more in a "happy" way, like when seeing an old friend.

Consequently, participants became more attuned to their tactile sensing, which caused a stronger connection (or, at least, an awareness of the interactions) between their emotional states and the experience of touch. The emphasis on touch-based communication seemed to evoke a heightened awareness towards the in-themoment nature of the experience, allowing participants to linger in liminal mental spaces, such as 'just doing what comes up,' 'being influenced in an indefinite way' and 'being playful.' As noted by Hertenstein and others (2006), these responses support the efficacy of social touch in emotional communications in that participants seemed to naturally embrace the open and non-judgmental nature of touch-based interaction.

The result was an artwork to be felt, and not seen: the participants were not performing, they were experiencing. The carefully created non-judgmental environment supported a temporary realm in which everyday gestures and simple physical contacts were given as many meanings as there were participants; everything was experimental, and nothing was wasted in the experimentations. Participants became free and unbound to ask, 'what if I...?,' 'what is this?,' and 'where is this going?' No one knew the answers, yet each person governed the turns in which every unfolding moment could take.

We noticed the choreographic potential of this non-hierarchical, inclusive and transformative environment. For instance, what are the implications of recognizing and illuminating organically occurring, everyday kinesthetic interactions between individuals as an artistic theme, and presenting this idea through an extended version of our project? How would such a presentation affect audience members? Moreover, would there be any boundaries between performer and audience? Moving forces and dynamics continuously unfold in time and space, no less in everyday situations than in improvisational 'performances.' Our experiential participatory performance created a co-performative context, which has redefined the ubiquitous experience of shared embodied interactions as a choreographic or performative tool. In this sense, our project expanded the boundaries of the conventionally defined concept of artistic performance: facilitators and participants as creators, performers and audience.

\section{Conclusion}

This project introduced an explorative method of investigating social interactions through the practice of movement improvisation. We argue that this type of shared experience can tap into an individual's ability to gain a deeper understanding on how our bodily senses, perceptions, and micro-actions play a role in our embodied interactions with others. At the same time, the project revealed that shared embodied knowledge is 
highly appreciated, particularly among those without previous experience with embodied, movement enquiry. It allows for a more fluid, honest, and raw mode of social cognition. We expanded the traditional boundaries of creative artwork; the participants were the 'creators' and 'audience members' of improvised experience, creating and attending to an experiential process that could be meaningful, both experientially by delving into a new sensory experience and artistically, as a work in progress.

Let's Improv It has an expansive character as a project 'in motion.' It could serve as an educational tool in dance education, which allows insight into movement experience from different perspectives. Additionally, it could be seen as performative event that connects performers and audience by offering an insight to the artistic creative process.

\section{Acknowledgements}

The authors would like to thank Adam Benjamin for his guidance and support during the project and detailed feedback on the paper, and the delegates at Off the Lip 2017: CogNovo Colloquium on Experiences and Applications of Cognitive Innovation for the vivid response to the performative presentation.

This work was supported by Plymouth University and CogNovo (FP7-PEOPLE-2013ITN-604764), a project funded by the EU Marie Skłodowska Curie programme.

\section{References}

Benjamin, A. (2002). Making an entrance: Theory and practice for disabled and non-disabled dancers. London, UK: Routledge.

Blom, L. A., \& Chaplin, L. T. (1988). The moment of movement: Dance improvisation. Pittsburgh, PA: University of Pittsburgh Press.

Burgoon, J. K., Guerrero, L. K., \& Floyd, K. (2016). Nonverbal communication. London, UK: Routledge.

Chatel-Goldman, J., Congedo, M., Jutten, C., \& Schwartz, J.-L. (2014). Touch increases autonomic coupling between romantic partners. Frontiers in Behavioral Neuroscience, 8. doi:10.3389/fnbeh.2014.00095

Dijksterhuis, A. (2005). Why we are social animals: The high road to imitation as social glue. In S. Hurley \& N. Chater (Eds.), Perspectives on imitation: From neuroscience to social science: Volume 2, Immitation, human development, and culture (pp. 207-220). Cambridge, MA: MIT Press.

Feldman, R. (2011). Maternal touch and the developing infant. In M. J. Hertenstein \& S. J. Weiss (Eds.), The handbook of touch: Neuroscience, behavioral, and health perspectives (pp. 373-407). New York, Springer.

Foster, S. L. (2003). Taken by surprise: Improvisation in dance and mind. In A. C. Albright \& D. Gere (Eds.), Taken by surprise: A dance improvisation reader (pp. 3-10). Middletown, CT: Wesleyan University Press. 
Gallese, V. (2003). The manifold nature of interpersonal relations: The quest for a common mechanism. Biological Sciences, 358(1431), 517-528. doi:10.1098/rstb.2002.1234

Gallese, V., Keysers, C., \& Rizzolatti, G. (2004). A unifying view of the basis of social cognition. Trends in Cognitive Sciences, 8(9), 396-403. doi:10.1016/j.tics.2004.07.002

Goldman, A. I., \& Sripada, C. S. (2005). Simulationist models of face-based emotion recognition. Cognition, 94(3), 193-213. doi:10.1016/j.cognition.2004.01.005

Hertenstein, M. J., Keltner, D., App, B., Bulleit, B. A., \& Jaskolka, A. R. (2006). Touch communicates distinct emotions. Emotion, 6(3), 528-533. doi:10.1037/1528-3542.6.3.528

Ignatow, G. (2007). Theories of embodied knowledge: New directions for cultural and cognitive sociology? Journal for the Theory of Social Behaviour, 37(2), 115-135.

Jones, S. E., \& Yarbrough, A. E. (1985). A naturalistic study of the meanings of touch. Communications Monographs, 52(1), 19-56.

Kraus, M. W., Huang, C., \& Keltner, D. (2010). Tactile communication, cooperation, and performance: An ethological study of the NBA. Emotion, 10(5), 745-749. doi:10.1037/a0019382

Linden, D. J. (2015). Touch: The science of hand, heart and mind. London, UK: Penguin.

Ng, S. H., \& Bradac, J. J. (1993). Power in language: Verbal communication and social influence. Thousand Oaks, CA: Sage.

Posner, M. I., Nissen, M. J., \& Klein, R. M. (1976). Visual dominance: An information-processing account of its origins and significance. Psychological Review, 83(2), 157-171. doi:10.1037/0033-295X.83.2.157

Ribeiro, M. m., \& Fonseca, A. (2011). The empathy and the structuring sharing modes of movement sequences in the improvisation of contemporary dance. Research in Dance Education, 12(2), 71-85. doi:10.1080/14647893.2011.575220

Savrami, K. (2017). A duet between science and art: Neural correlates of dance improvisation. Research in Dance Education, 1-18. Advance online publication. doi:10.1080/14647893.2017.1369509

Sawyer, R. K. (2000). Improvisation and the creative process: Dewey, Collingwood, and the aesthetics of spontaneity. The Journal of Aesthetics and Art Criticism, 58(2), 149-161. doi:10.2307/432094

Sebanz, N., Bekkering, H., \& Knoblich G. (2006). Joint action: Bodies and minds moving together. Trends in Cognitive Sciences, 10(2), 70-76. doi:10.1016/j.tics.2005.12.009

Theiner, G. (2014). Varieties of group cognition. In L. A. Shapiro (Ed.), The Routledge handbook of embodied cognition (pp. 347-357). New York, NY: Routledge.

Verstegen, I. (2005). Arnheim, gestalt and art, A psychological theory. Vienna: Springer.

White, K. (2004). Touch: Attachment and the body: Introduction to the John Bowlby Memorial Conference 2003. In K. White (Ed.), Touch: Attachment and the Body (pp. xxii-xxv). London, UK: Karnac. 


\section{Response to “Let's Improv It: The Embodied Investigation of Social Collabora- tion" by John Matthias}

This is a really interesting paper-the methods undertaken within the improvising group are very pertinent and questions and contexts posed in the opening paragraph warrant major attention. Given the nature of this work and the importance of this kind of interaction, it seems important to ask the question: "why is this kind of interactive activity not a more common everyday activity in the West?" It feels as though the group-based movement-based creation such as outlined in this paper should be integrated soundly within our education system. The comment about the dual role of participants and audience is particularly interesting and perhaps offers one possible answer to my previous question. Perhaps we are still not used to being participants in art-creation as a whole and are more comfortable with a more passive role? It would be good to have a discussion about how we could bring group movement practice such as that outlined here more into mainstream practice as is more common in other cultures. 